\title{
Evaluation of wind energy potential in the south-south geopolitical zone of Nigeria
}

\author{
*11 EBOIBI, B; ${ }^{2}$ EBOIBI, O; ${ }^{1}$ OKUBIO, E; ${ }^{1}$ IYASELE, C \\ ${ }^{I}$ Department of Chemical Engineering, Delta State University, Oleh Campus. P.M.B.22, Oleh, Delta State, Nigeria \\ ${ }^{2}$ Department of Mechanical Engineering, Delta State Polytechnic, P.M.B. 05, Ozoro, Delta State, Nigeria. \\ *corresponding author Email: blessingeboibi@ gmail.com
}

\begin{abstract}
This study examined wind energy potential of six selected locations the South-South geopolitical zone of Nigeria using 10 year wind data obtained at a height of $10 \mathrm{~m}$ as a possible location for energy generation from wind. The obtained data showed that the annual mean wind speed for Asaba, Benin, Calabar, Port Harcourt, Uyo, and Warri were $3.3 \mathrm{~m} / \mathrm{s}, 3.3 \mathrm{~m} / \mathrm{s}, 4.4 \mathrm{~m} / \mathrm{s}, 3.4 \mathrm{~m} / \mathrm{s}, 3.5 \mathrm{~m} / \mathrm{s}$ and $3.7 \mathrm{~m} / \mathrm{s}$ respectively, with corresponding mean power density of $21.8 \mathrm{~W} / \mathrm{m}^{2}, 21.4 \mathrm{~W} / \mathrm{m}^{2}, 35.8 \mathrm{~W} / \mathrm{m}^{2}, 23 \mathrm{~W} / \mathrm{m}^{2}, 25.2 \mathrm{~W} / \mathrm{m}^{2}$, and $30.8 \mathrm{~W} / \mathrm{m}^{2}$. The mean energy output of $183.4 \mathrm{KWh} / \mathrm{m}^{2}$, $205.4 \mathrm{KWh} / \mathrm{m}^{2}, 311.7 \mathrm{KWh} / \mathrm{m}^{2}, 200.9 \mathrm{KWh} / \mathrm{m}^{2}, 220.9 \mathrm{KWh} / \mathrm{m}^{2}$, and $274.3 \mathrm{KWh} / \mathrm{m}^{2}$ were found for the respective locations. The corresponding annual mean wind speed with maximum energy ranged from $4.1 \mathrm{~m} / \mathrm{s}$ to $4.4 \mathrm{~m} / \mathrm{s}$ with Calabar station found to be the most suitable site for the installation of wind turbine for power generation. The overall mean wind power densities and the annual mean power densities were under class 1 of wind classification scheme indicating that, the mean wind speed fell short of required standard of $6 \mathrm{~m} / \mathrm{s}$ for large-scale installation of wind energy generation. Nevertheless, the power generated could be improved using suitable wind turbines at reasonable heights.
\end{abstract}

\section{DOI: https://dx.doi.org/10.4314/jasem.v21i7.14}

Copyright @ 2017 Eboibi et al. this is an open access article distributed under the Creative Commons Attribution NonCommercial License (CC-BY-NC), which permits unrestricted use, distribution, and reproduction in any medium, provided the original work is properly cited.

Received 10 September 2017, received in revised form 15 October 2017, accepted 02 December 2017.

Keywords: Mean wind speed, Wind power density, Wind energy, Renewable energy.

Due to rapid growth in population, industrialization, and pollution, the world is constantly in search of several means to increase her energy resources in order to meet the increasing demand for renewable energy. Non renewable energy sources including fossil fuels, coal and natural gas accounts for up to $84 \%$ of energy production, while the remaining $16 \%$ is from renewable, nuclear and other energy sources (Bansal, 2006). Apparently, conventional energy sources leads to environmental and ecological hazards, global warming, greenhouse gas effect and acid rain. Thus leading to increase research interest on alternative renewable energy sources that are sustainable and environment friendly.

Awareness of the importance and benefits achievable from generation of energy from renewable energy sources other than fossil fuel has encouraged interest in wind energy (Eboibi et al., 2016) and other renewable energy sources. Nema et al., (2009) explained the importance of generating energy from renewable sources through a review of hybrid energy system that combines wind and PV-solar as a realistic technology to compliment energy generation from engine-driven energy sources. Thus embracing wind energy technology in Nigeria could help to alleviate the energy crises in the country. Nigeria with a population of over one hundred and seventy million barely generates meager $6000 \mathrm{MW}$ of electricity. By international standard, the produced power is not enough to sustain healthy living let alone to support infrastructure and industrial development. The energy crisis could be traceable to the ailing four refineries that are currently producing at 30\% of installed capacity (Ajayi and Ajanuku, 2009).

Even with the prevailing energy crisis bedeviling the country, wind energy resources are not exploited. Non-exploitation of wind resources and lack of research interest in wind energy technology in Nigeria could be due to poor government policy in the energy sector. These factors have resulted in few studies in wind energy technology in Nigeria and with limited publications in literature. Some studies on assessment of wind resources on specific sites and regions in Nigeria have been investigated (Asiegbu, and Iwuoha, 2007; Fagbenle et al., 2011; Fadare, 2008; Nze-Esiaga and Okogbue, 2014; Ohunakin, 2011; and Okeniyi et al., 2015). These reported studies demonstrated the feasibility of harnessing wind energy as an alternative to conventional fossil fuel. However, there is limited report on the potentials of wind energy generation in the SouthSouth geopolitical zone of Nigeria. Therefore, this paper aims at evaluating wind energy potentials in the south-south region to select an appropriate location for the installation of wind turbines for power generation. 


\section{MATERIALS AND METHOD}

The materials used in this present study were the wind speed and wind direction data of six selected locations. Metrological data were obtained from the archive of the Nigerian Metrological agency, Oshodi, Lagos state. The information on the data sheet include wind speed and wind direction covering a period of ten (10) years (from 2003 to 2012).The selected locations include Asaba, Benin, Calabar, Port Harcourt, Uyo and Warri. The geographical locations of the selected stations are presented in Table 1.
These collected data for the six locations were analyzed for the annual mean wind speed, mean power density and mean energy output of the selected stations under study. Statistical method has been developed and used to analyze the wind energy characteristics based on literatures. The method considered the gamma distribution function of two parameters, normal and lognormal methods, Rayleigh distribution and the two parameter Weibull distribution that depends on scale (c) and shape (K) parameters and provides results with the best goodness-of-fit for and statistical significance (Akpinar and Akpinar, 2005).

Table 1: Geographical location of the selected stations

\begin{tabular}{lllll}
\hline & & & \\
STATION & LATITUDE & LONGITUDE & ALTITUDE & MERIOD OF \\
\hline Asaba & $6^{0} 122$ & $6^{0} 442$ & 57 & $2003-2012$ \\
Benin & $6^{0} 206$ & $5^{0} 3739$ & 78 & \\
Calabar & $4^{0} 576$ & $8^{0} 199$ & 94 & \\
Port Harcourt & $4^{0} 4639$ & $7^{0} 048$ & 508 & \\
Uyo & $5^{0} 160$ & $7^{0} 048$ & 252 & \\
Warri & $5^{\circ} 3112$ & $5^{\circ} 450$ & 18 & \\
\hline
\end{tabular}

Wind data for a given location can be characterized by probability density and cumulative distribution. Of which the Weibull density function is used to describe the wind speed frequency distribution at a given velocity $\mathrm{V}$, while the Weibull cumulative distribution function of velocity $\mathrm{V}$, gives the probability that the wind velocity is equal to or lower than $\mathrm{V}$, or within a given wind speed range (Oyedepo et al., 2012).

Average Wind speed:

One of the most important information on the wind spectra available at a location is its average velocity. In simple terms, the average velocity $(\mathrm{Vm})$ is given in Eq. (1)

$V m=\frac{1}{n} \sum_{i=1}^{\mathrm{n}} \mathrm{Vi}$

where $\mathrm{Vi}$ is the wind velocity and $\mathrm{n}$ the number of wind data

For the purpose of wind power density determination, it has been observed that Eq. (1) underestimates the wind power potential by 20 per cent. Therefore, it is more accurate to use the Eq. (2) given as

$\mathrm{Vm}=\left(\frac{1}{n} \sum_{i=1}^{n} \mathrm{vi}^{3}\right)^{\frac{1}{3}}$

The general Weibull two parameters expression is given as follows;

(a) Probability density function

$\mathrm{f}(\mathrm{v})=\left(\frac{k}{c}\right)\left(\frac{v}{c}\right)^{k-1} \exp \left[-\left(\frac{v}{c}\right)^{k}\right]$

$(\mathrm{k}>0, \mathrm{v}>0, \mathrm{c}>1)$

where $\mathrm{v}$ is the wind speed $(\mathrm{m} / \mathrm{s}), \mathrm{c}$ is the Weibull scale parameter $(\mathrm{m} / \mathrm{s})$ expressed as
$c=\frac{V m}{\Gamma\left(1+\frac{1}{\mathrm{k}}\right)}$

This expression gives the relationship between the Weibull scale (c), shape (k), and the average wind speed $V m$. where, $\Gamma$ is gamma function.

Alternatively, the Weibull scale factor can be estimated from Eq. (5)

$c=\frac{V m k^{2.6674}}{0.184+0.816 k^{2.73855}}$

$\mathrm{k}=$ Weibull dimensionless shape parameter expressed as

$k=\left(\frac{\partial}{V m}\right)^{-1.086}$

$\partial=$ standard deviation expressed as

$\partial=\sqrt{\frac{1}{\mathrm{n}} \sum_{i=1}^{n}(\mathrm{Vi}-\mathrm{Vm})^{2}}$

(b) Cumulative distribution function

$F V=1-\exp \left[-\left(\frac{v}{c}\right)^{k}\right]$

Weibull cumulative distribution function is an integral of the probability density function, it is modified from the equation of the probability density function $\mathrm{f}(\mathrm{v})$ when $\mathrm{k}=2$ (i.e. if $\mathrm{k} \neq 2$ makes the probability density distribution unimodal, $\mathrm{f}(\mathrm{v})$ is zero for discrete wind speed close to zero). Hence the equation becomes Rayleigh distribution which is a special case of Weibull distribution with $\mathrm{c}=1.13 \mathrm{v}_{\mathrm{m}}$, where $\mathrm{v}_{\mathrm{m}}=$ annual mean wind speed (Eboibi et al., 2014).

Wind speed variation with height: 
The power law expression gives the expression for the wind data measured at a different height other than that of the wind turbine hub height

$\frac{V}{V o}=\left(\frac{H}{H o}\right)^{\propto}$

where $v=$ wind speed at hub height at hub height $\mathrm{h}$, $\mathrm{v}_{0}=$ wind speed at original height at height $\mathrm{h}_{0}, \alpha$ is assumed to be $1 / 7=0.143$, which is the surface roughness coefficient of the turbine (Youm et al., 2000)

Power in the wind: The governing equation for power extraction is given as $P=F x V$, where $P=$ power in the wind, $F=$ force vector and $V=$ velocity of the moving wind turbine. The average power that can be extracted from the wind by a wind turbine varies with the cube of the average wind speed (Templin 1974) given as;

$P=\frac{1}{2} C p A V^{3}$

Where $P=$ aerodynamic power (watt), $A=$ area of wind turbine rotor $\left(\mathrm{m}^{2}\right), v=$ wind speed $(\mathrm{m} / \mathrm{s}), \mathrm{p}=$ air density $\left(1.225 \mathrm{~kg} / \mathrm{m}^{3}\right)$, and $C_{p}=$ coefficient of power which is the most important variable in wind turbine aerodynamics. The power coefficient is the fraction of power in the wind captured by a wind turbine (Agbetuyi et al., 2012; Eboibi et al., 2016).

The mean wind power density $\mathrm{P}_{\mathrm{D}}$ was estimated using (Eq. 11)

$P_{D}=\frac{P(v)}{A}=\frac{1}{2} \quad \mathrm{Vm}^{3}$

where $P(v)$ is wind power in watt, $P_{D}$ is the wind power density in watt per square meter

Energy from the wind:

The available energy per unit area perpendicular to the wind stream over a given period of time, $t$ at a wind speed $\mathrm{v}$, is expressed by the kinetic energy flux (Youm et al., 2012) as shown in Eq. (12).

$\mathrm{E}=\frac{1}{2} \quad \mathrm{vm}^{3} \mathrm{t}=\mathrm{P}_{\mathrm{D}} \times \mathrm{t}$

where $\mathrm{E}$ is the theoretical total energy available for the wind turbine to do work.

\section{RESULTS AND DISCUSSION}

The results obtained for the mean power density, mean energy density and annual wind speed for Asaba station is presented in Figure 1. As illustrated in Figure 1, the mean power density distribution shows maximum power of $43.2 \mathrm{~W} / \mathrm{m}^{2}$ in 2011 , and minimum of $5.5 \mathrm{~W} / \mathrm{m}^{2}$ in 2009 . It was found that the minimum value was the lowest amongst all selected stations. However it does not mean that the highest power density estimated in this station is not as high as in other stations, which will be discussed later. Also the maximum mean energy output in this station was found in 2011 with a value of $378 \mathrm{KWh} / \mathrm{m}^{2}$ and the minimum $48.3 \mathrm{KWh} / \mathrm{m}^{2}$ in 2009 . There were significant variations in wind speed distribution with inconsistencies in wind speed across measurement period. The minimum annual mean wind speed was $2.1 \mathrm{~m} / \mathrm{s}$ in 2009 and $4.1 \mathrm{~m} / \mathrm{s}$ (in 2011) the maximum.

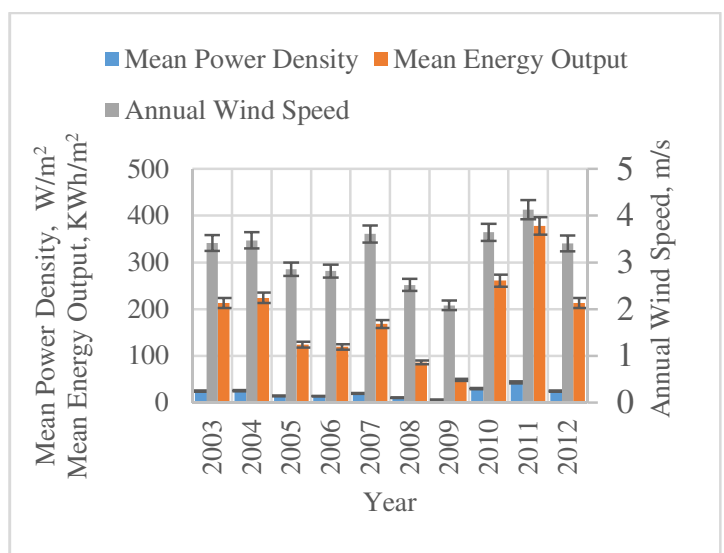

Fig 1: Wind characteristics (mean power density, mean energy output and annual wind speed) for Asaba.

The wind characteristics for Benin station is presented in Figure 2. Based on the data presented in Figure 2, similar trend occurred between Benin and Asaba stations, though with significant differences in data. Also, it shows that the highest wind power potentials occurred in 2004. The values of the mean wind power density and mean energy output were between $13.9 \mathrm{~W} / \mathrm{m}^{2}$ and $121.6 \mathrm{KWh} / \mathrm{m}^{2}$, and $51.8 \mathrm{~W} / \mathrm{m}^{2}$ and $453.4 \mathrm{KWh} / \mathrm{m}^{2}$ respectively. In addition, the annual wind speed was between $2.8 \mathrm{~m} / \mathrm{s}$ in 2008 and $4.4 \mathrm{~m} / \mathrm{s}$ in 2004, which was found to be higher when compared to that of Asaba station. This variation could be due to differences in years, topography and roughness of locations (ECN-UNDP, 2005)

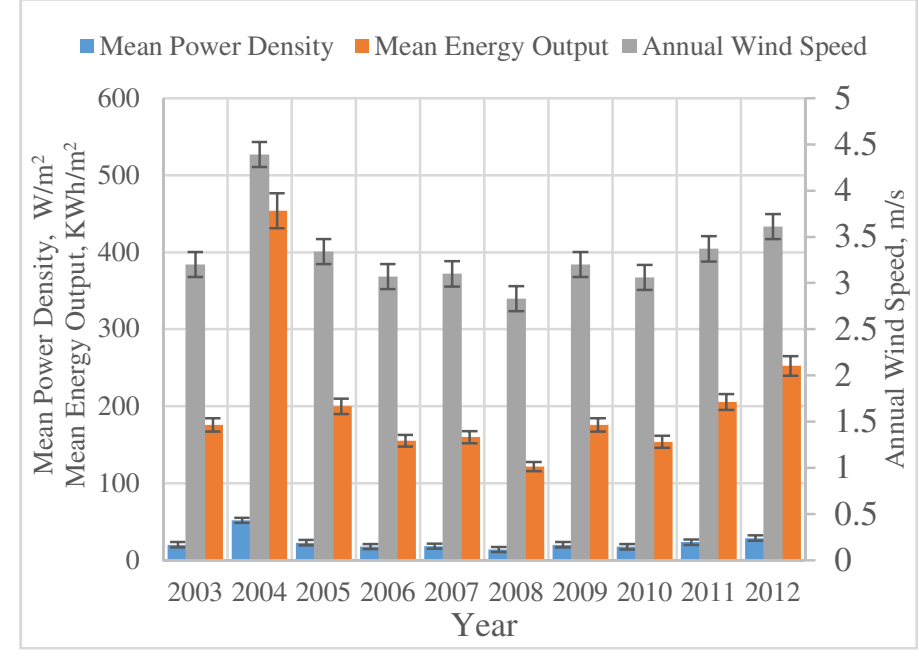

Fig 2: Wind characteristics (mean power density, mean energy output and annual wind speed) for Benin. 
This study has shown that the wind characteristics vary with stations irrespective of same year of measurement. As shown in Figure 3, Calabar station has a more consistent annual mean wind speed in all years when compared to other stations such as Benin and Asaba that shows more frequent fluctuations in measured values. For example, the annual mean wind speed for Calabar station were in the range of $3.6 \mathrm{~m} / \mathrm{s}$ to $4.5 \mathrm{~m} / \mathrm{s}$, while Benin was $2.8 \mathrm{~m} / \mathrm{s}$ to $4.4 \mathrm{~m} / \mathrm{s}$; and Asaba $2.1 \mathrm{~m} / \mathrm{s}$ to $4.1 \mathrm{~m} / \mathrm{s}$. Similar trends were observed for the mean power density and energy output. These findings were found to be within range of previous report. For example, Okeniyi et al., (2015) reported mean wind speed and power density of $4.42 \mathrm{~m} / \mathrm{s}$ and $52.72 \mathrm{~m} / \mathrm{s}$, respectively, for Calabar.

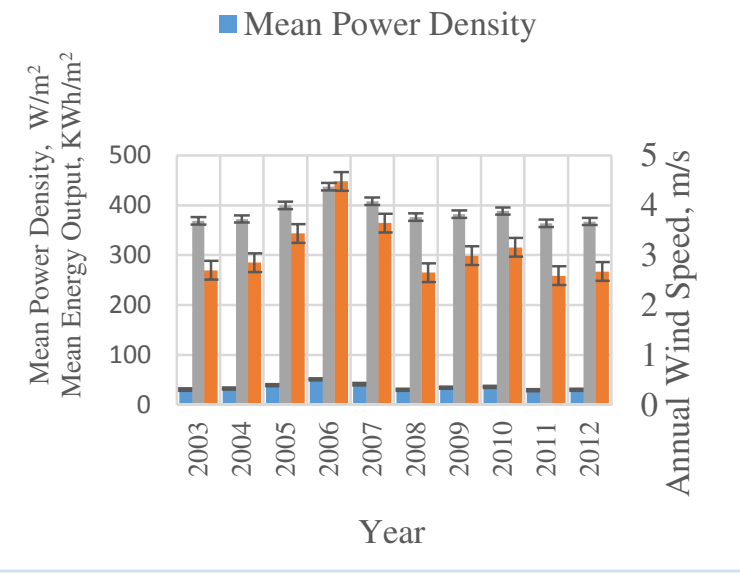

Fig 3: Wind characteristics (mean power density, mean energy output and annual wind speed) for Calabar.

Furthermore, the annual mean power density and energy output for Calabar station also shows similar variations as that of Warri, which will be discussed later. Importantly, the data (power densities) obtained for Calabar station were found to be under 'class 1' of the wind power classification scheme (Ilinca et al., 2003). Suggesting that Calabar station seems to be more viable for wind power generation in the SouthSouth geopolitical zone of Nigeria.

The estimated mean power density, mean energy output and mean wind speed characteristics for Port Harcourt from 2003 to 2012 are presented in Figure 4. Based on data presented in Figure 4, the maximum power density was achieved in 2005. Also the year 2005 recorded the maximum annual mean wind speed in this reported study. The maximum values for Calabar were $52.5 \mathrm{~W} / \mathrm{m}^{2}$ and $456.4 \mathrm{KWh} / \mathrm{m}^{2}$ for the mean power density and mean energy output, respectively. Minimum value of $5.8 \mathrm{~W} / \mathrm{m}^{2}$ and $51.2 \mathrm{KWh} / \mathrm{m}^{2}$ were achieved in 2010 . Generally, the maximum mean power density and mean energy output for any given year across the measurement period estimated in 2005 was obtained for Port
Harcourt station. This finding suggests that Port Harcourt station has the highest wind power generating capacity, hence a potential site for wind energy generation. However when compared to Calabar station there were significant and unsteady variations in the wind speed characteristics for Port Harcourt station, suggesting that wind generation may not be fully reliable.

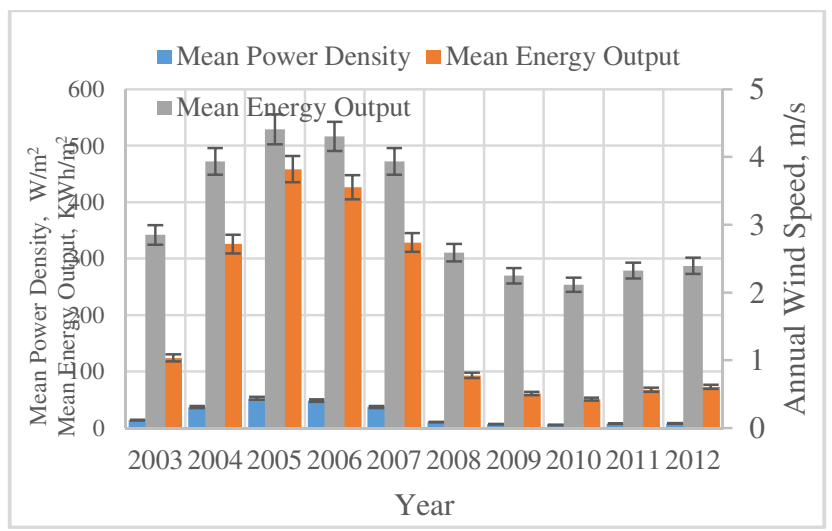

Fig 4: Wind characteristics (mean power density, mean energy output and annual wind speed) for Port Harcourt.

In addition, the annual mean wind speed were high (about 4m/s ) between the 2004 and 2007, however there were significant decreases from $4 \mathrm{~m} / \mathrm{s}$ to $2.1 \mathrm{~m} / \mathrm{s}$ between 2008 and 2012. Consequently, this period accounted for the minimum values obtained for Port Harcourt station. Similarly the decrease in the annual mean wind speed also corresponded with decrease in the mean power density and energy output. There could be several reasons behind this phenomenon, one of which could be due to changes in direction of wind, time and space. Ohunakin (2011) reported that South-Westerly (SW) and Westerly (W) wind effects led to achievement of high values while the NorthEasterly (NE), Easterly (E) and North-Westerly (NW) winds led to low wind data during the period of their study. A study on the influence of wind directions on wind data characteristics could be an interesting research. As it could improve the potentials of Port Harcourt station for wind energy generation

Unlike the significant decrease observed for Port Harcourt station, Uyo station had a steady wind speed characteristics. The annual wind speed was between $\sim 3 \mathrm{~m} / \mathrm{s}$ to $4.2 \mathrm{~m} / \mathrm{s}$ between 2008 and 2012. Although Port Harcourt station had higher annual wind energy from $3.9 \mathrm{~m} / \mathrm{s}$ to $4.3 \mathrm{~m} / \mathrm{s}$ between 2004 and 2007 compared to $3 \mathrm{~m} / \mathrm{s}$ to $3.8 \mathrm{~m} / \mathrm{s}$ for Uyo, the data obtained for Uyo were more consistent. The ranges in variation between years were lower compared to that obtained for Port Harcourt. Furthermore, the 
maximum mean wind power density and mean energy output were estimated as $43.8 \mathrm{~W} / \mathrm{m}^{2}$ and $383.5 \mathrm{KWh} / \mathrm{m}^{2}$ in the year 2012 , and the minimum $14.0 \mathrm{~W} / \mathrm{m}^{2}$ and $122.9 \mathrm{KWh} / \mathrm{m}^{2}$ in 2006 . These findings are still under the 'class 1' of the pacific Northwest Laboratory (PNL) wind power classification scheme, as mentioned previously.

Based on the data presented in Figure 5, it is clear that the year 2012 was the most favorable for wind power utilization of all the years within measurement periods. When compared to previous stations reported, Uyo station had a higher mean annual wind speed, power density, and energy output of $4.2 \mathrm{~m} / \mathrm{s}$, $43.8 \mathrm{~W} / \mathrm{m}^{2}$ and $383.5 \mathrm{KWh} / \mathrm{m}^{2}$, respectively, in the year 2012. This finding could be important in terms of modelling wind characteristics for power generation. However, the focus of this study was to find a suitable location that has more potentials for wind energy generation in the South -South geopolitical zone of Nigeria.

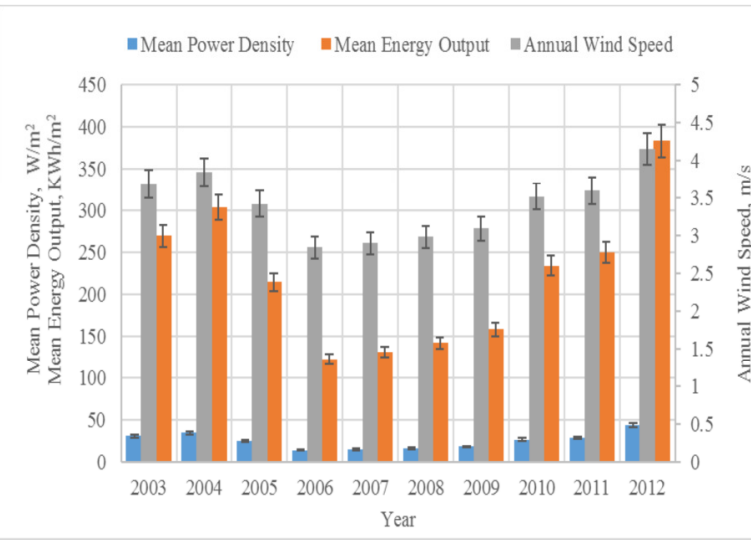

Fig 5: Wind characteristics (mean power density, mean energy output and annual wind speed) for Uyo.

Furthermore, the mean power density and mean energy output for Warri station are presented in Figure 6. As shown in Figure 6, there were gradual increase in the mean power density and mean energy output from 2003 to 2005. Fluctuation in power densities and energy output occurred from 2006 to 2012. Warri has its minimum values of mean power density and mean energy output as $20.6 \mathrm{~W} / \mathrm{m}$ and $196.3 \mathrm{KWh} / \mathrm{m}^{2}$, respectively, in 2008. Maximum values of $50.7 \mathrm{~W} / \mathrm{m}^{2}$ for mean power density and $444.8 \mathrm{KWh} / \mathrm{m}^{2}$ for the mean energy output was obtained in 2005. Also the annual wind speed where the maximum wind speed $(4.4 \mathrm{~m} / \mathrm{s})$ was found to occur in 2005 and the minimum $(3.2 \mathrm{~m} / \mathrm{s})$ in 2008 . These findings were found to be within the range of previous report. Okeniyi et al., (2015) reported mean wind speed of $3.95 \mathrm{~m} / \mathrm{s}$ and $37.04 \mathrm{~m} / \mathrm{s}$ for the power density for Warri.
Although the reported wind power densities could be classified under 'class 1', $6 \mathrm{~m} / \mathrm{s}$ has been reported (Sathyajith, 2006) as the average wind speed required for large wind power generation.

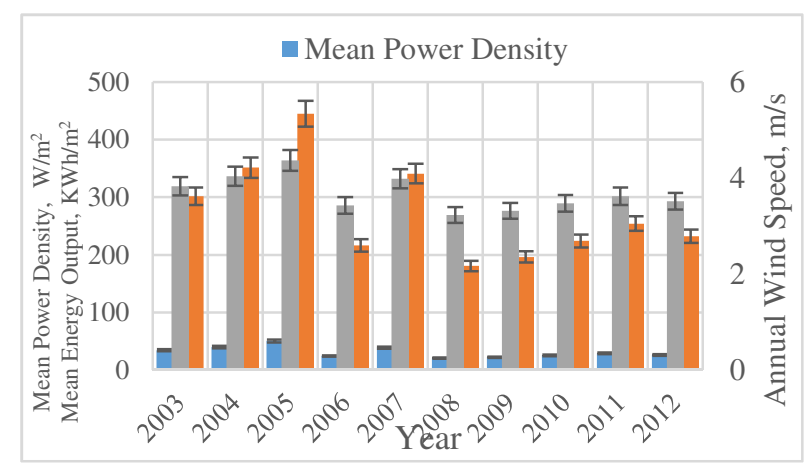

Fig 6 Wind characteristics (mean power density, mean energy output and annual wind speed) for Warri

The characteristics behavior of the wind speed seems to have direct effect on the power density and energy output. Consequently, a fluctuation in wind speed data corresponds with that obtained for the power density and energy output, as shown in Figure 6. The fluctuation in the wind speed could be due to the variations in values of power densities and energy output which is in agreement with Ohunakin, (2011) who reported wind characteristics of Uyo, Nigeria.

Conclusively, this reported study has shown the wind characteristics of different locations in the SouthSouth geopolitical zone of Nigeria. Based on the results of this study the lowest annual mean wind speed occurred in Asaba station with an annual mean wind speed of $2.1 \mathrm{~m} / \mathrm{s}$ in the year 2009. In 2005, the maximum annual mean wind speed of $4.4 \mathrm{~m} / \mathrm{s}$ was obtained for Port Harcourt station. It could therefore be concluded that the annual mean wind speed distribution in the selected locations varies from $2 \mathrm{~m} / \mathrm{s}$ to $4.4 \mathrm{~m} / \mathrm{s}$, which could be classified as low to moderate wind speed. Also Calabar station was found to have the most probable mean wind speed in the period of study at a value of $\sim 4.4 \mathrm{~m} / \mathrm{s}$, hence has a more wind power potentials followed by Warri station with a value of $3.7 \mathrm{~m} / \mathrm{s}$. Benin station was found to have least mean wind speed of $3.3 \mathrm{~m} / \mathrm{s}$.

Based on these findings, it could be stated that Calabar Station when compared to Asaba, Benin, Port Harcourt, Uyo and Warri is more viable for wind power generation in the South-South geopolitical zone of Nigeria. Warri Station has a relative high annual mean wind speed, mean power density and mean energy and could also be considered for wind power generation. The power output from these selected locations could be enhanced by the use of 
large turbine capacity rating mounted at a relatively higher height (50 to 100 meters) above the ground (Nze-Esiaga and Okogbue, 2014; Okeniyi et al., 2015 ) in other to capture faster wind.

The findings of this study has shown that all the measured mean wind speed data were found to be lower than the $6 \mathrm{~m} / \mathrm{s}$ required for large or medium scale wind power generation. Therefore, medium or large scale wind power generation in these locations may not be feasible. However, the wind power generated can be channeled towards small wind farm installation, which could be used for low-power applications such as serving the electricity need of remote areas, small villages or individuals in the offgrid areas. Also, it could be used for water pumping in other to improve agricultural yield by means of irrigation and as well as to serve other mechanical purposes. Nevertheless, it has been reported that recent turbine designs can generate electricity from an annual wind energy speed $>3.0 \mathrm{~m} / \mathrm{s}$ (Nze-Esiaga and Okogbue, 2014). Suggesting installation of this modern wind turbine designs at the locations investigated could generate electricity.

Conclusion: The study has shown the wind speed characteristics, wind power densities and the wind energy output of six (6) selected locations in the South-South geopolitical zone of Nigeria. Calabar station was found to have the maximum wind speed potential amongst all the analyzed stations (Asaba, Benin, Port Harcourt and Uyo), however, it may not be applied to large scale power source. Nevertheless, the power generated could be improved, using large powerful turbines connected to an off grid, generating higher than the one originally generated.

\section{REFERENCES}

Ajayi OO; Ajanaku KO (2009) Nigeria's energy challenge and power development: the way forward. Energy and Environment, 20: 411-413

Akpinar EK; Akpinar S (2005) A Statistical Analysis of Wind Speed Data Used in Installation of Wind Energy Conversion Systems. Energy Convers. Mgt., 46: 515532

Asiegbu AD; Iwuoha GS (2007) Studies of wind resources in Umudike, South East Nigeria-an assessment of economic viability. Journal of Engineering and Applied Sciences, 2: 1539-1541.

Bansal RC (2006) Automatic reactive power control of wind-diesel hybrid power systems. IEEE Transaction on Industrial Electronics, 53:1116-26.

Eboibi O; Danao LAM; Howell RJ (2016) Experimental investigation of the influence of solidity on the performance and flow field aerodynamics of vertical xis wind turbines at low Reynolds number. Renewable Energy, 92:474 - 483.

Eboibi O; Howell R; Danao LA (2014) A Numerical Study on the Influence of Solidity on the performance of vertical axis wind turbines. Philippine Engineering Journal, 92: 474-483.

Energy Commission of Nigeria and United Nations Development Programme (ECN-UNDP) (2005) Renewable Energy Master Plan: Final Draft Report. http://www.iceednigeria.org/workspace/uploads/nov.2005.

Fadare DAA (2008) Statistical analysis of wind Energy potential in Ibadan, Nigeria, based on Weibull distribution function. The Pacific Journal of Science and Technology, 9: 110-119.

Fagbenle RL; Katende J; Ajayi OO; Okeniyi JO (2011) Assessment of wind energy potential of two sites in North-East, Nigeria. Renew. Energy 36:1277-1293.

Ilinca A; McCarthy E; Chaumel J-L; Retiveau, J-L (2003) Wind potential assessment of Quebec Province. Renew. Energy 28: 1881-1897.

Nema P; Nema RK; Rangnekar S (2009) A current and future state of art development of hybrid energy system using wind and PV-solar: a review. Renewable and sustainable energy reviews, 13: 2096-2103.

Nze-Esiaga N; Okogbue EC (2014) Assessment of Wind Energy Potential as a Power Generation Source in Five Locations of South Western Nigeria. Journal of Power and Energy Engineering, 2: 1-13.

Ohunakin OS (2011) Wind characteristics and wind energy assessment in Uyo Nigeria. Journal of Engineering and Applied Sciences, 6: 141-146.

Okeniyi JO; Ohunakin OO; Okeniyi ET (2014) Assessments of wind - energy potential in selected sites from three geopolitical zones in Nigeria: implications for renewable/sustainable rural electrification. The Scientific World Journal, 1-14.

Oyedepo SO; Muyiwa SA; Samuel SP, (2012) Analysis of Wind Speed Data and Wind Energy Potential in Three Selected Locations in South-East Nigeria. International Journal of Energy and Environmental Engineering, 3:7.

Sathyajith M (2006) Wind Energy Fundamentals, Resource Analysis and Economics. Springer, Neitherland.

Templine RJ (1974) The damens turbine: a performance prediction model using steamtables. Sandia National Laboratories, Albuquerque, New Mexico, USA.

Youm I; Sarr J; Sall M; Ndiaye A; Kane MM (2012) Analysis of Wind Data and Wind Energy Potential along the Northern Coast of Senegal. Rev. Energ. Ren. 8: $95-108$. 